PAEDIATRIC LUNG DISEASE

\title{
The safety and quality of endobronchial biopsy in children under five years old
}

\author{
S Saglani, D N R Payne, A G Nicholson, M Scallan, E Haxby, A Bush
}

Thorax 2003;58:1053-1057

See end of article for authors' affiliations .....................

Correspondence to: Dr Andrew Bush, Department of Paediatric Respiratory Medicine, Royal Brompton Hospital, Sydney St, London SW3 6NP, UK:

a.bush@

rbh.nthames.nhs.uk

Received 20 March 2003 Accepted for publication 9 July 2003
Background: Little is known about the airway pathology of wheezing disorders in infants and preschool children, partly owing to the difficulty of undertaking invasive studies in this age group. The safety of endobronchial biopsy and the quality of biopsies obtained were reviewed in infants and preschool children.

Methods: Case notes of children under five years of age who underwent bronchoscopy and endobronchial biopsy were reviewed. The safety of the procedure was compared in a control group matched for weight and age, undergoing bronchoscopy without endobronchial biopsy. A consultant histopathologist assessed biopsy quality.

Results: 33 patients (mean age 31 months, range 4 to 59) underwent bronchoscopy and endobronchial biopsy, and were matched with 33 controls (mean age 28 months, range 3 to 52). There was no significant difference between groups in the number, type, or severity of complications occurring during or after the procedure. Biopsies from 30 of the 33 subjects could be assessed. Reticular basement membrane was identified in all 30; inflammation could be assessed in 26; areas of smooth muscle were present in 23. Conclusions: In a group of preschool children undergoing bronchoscopy under general anaesthetic, performance of endobronchial biopsy carried no extra risk. The quality of biopsies obtained was usually sufficient to allow an assessment of remodelling and inflammation.
W heezing in infants and preschool children is common $^{1}$ and can be severe, causing significant morbidity. ${ }^{2}$ The majority of children will grow out of their symptoms by school age, ${ }^{3}$ although a proportion will continue to wheeze in later childhood and be given a diagnosis of asthma. ${ }^{4}$ Despite the identification of certain risk factors - such as atopy and egg allergy-for the development of asthma in preschool children with wheeze, ${ }^{56}$ it remains difficult to predict which children will go on to develop asthma. ${ }^{7}$ As a result, the treatment of wheeze in infants and preschool children remains unsatisfactory. ${ }^{8} 9$

Studies in adult asthma involving endobronchial biopsy have allowed detailed investigation of the cellular and molecular mechanisms of asthma, ${ }^{10}{ }^{11}$ and some information is also now available about asthma in older children. ${ }^{12-14}$ Similarly, investigation of airway pathology in infants and preschool children with wheeze should help us to understand more about the basis of wheeze in this age group, particularly the role of airway inflammation. The extent and pattern of inflammation may help to guide the use of anti-inflammatory drug treatment in a similar way to that used in patients with established asthma.

In view of the paucity of information regarding the pathology of asthma and wheeze in early childhood, the need for further research in this age group has been highlighted. ${ }^{15}{ }^{16}$ However, there has been some reluctance on the part of investigators to undertake invasive studies in very young children because of ethical dilemmas surrounding safety. There is also an issue of biopsy size and quality. Typically, adult biopsies are taken through a bronchoscope with a $2.8 \mathrm{~mm}$ channel, and in older children with a $2.2 \mathrm{~mm}$ channel. However, in small children a bronchoscope with a $1.2 \mathrm{~mm}$ channel has to be used. At our centre in the last two years, increasing numbers of children under the age of five undergoing bronchoscopy have also had endobronchial biopsies and bronchoalveolar lavage, to provide additional information about the inflammatory component in cough and wheeze, and for diagnostic confirmation in suspected pulmonary tuberculosis.

If endobronchial biopsy is to be used to investigate the pathology of wheezing disorders in infants and preschool children, it is essential that the procedure is safe and that good quality biopsies can be obtained. Our aim in this report was therefore to investigate whether the performance of endobronchial biopsy in preschool children undergoing flexible bronchoscopy increases the risk of the procedure, and to examine whether biopsies so obtained were of suitable quality for research.

\section{METHODS}

Subjects: patients having flexible bronchoscopy and endobronchial biopsy

The case notes of 33 children (mean age 31 months, range 4 to 59 ; mean weight $12.6 \mathrm{~kg}$, range 5.1 to 18.8 ), in whom bronchoscopy and endobronchial biopsy were done by one consultant respiratory paediatrician $(\mathrm{AB})$ at the Royal Brompton Hospital between January 2000 and November 2002, were evaluated for information about the general anaesthetic and about any complications that occurred during or after the procedure.

\section{Controls: patients having flexible bronchoscopy without endobronchial biopsy}

Thirty three controls matched for weight and age (mean age 28 months, range 3 to 52 ; mean weight $12.5 \mathrm{~kg}$, range 4.7 to 18.4), in whom flexible bronchoscopy without endobronchial biopsy had been done by the same bronchoscopist during the same period, were identified from the database. Information concerning the general anaesthetic and complications was obtained from the case notes.

\section{Consent}

Fully informed consent for the bronchoscopy/BAL/endobronchial biopsy was obtained from the parents of all the patients. 


\section{Anaesthesia}

Flexible bronchoscopy was done in theatre under general anaesthesia. The details of anaesthetic administration at our centre have been described previously. ${ }^{17}$

\section{Flexible bronchoscopy}

The bronchoscope to be used was determined by the age of the child. A $2.7 \mathrm{~mm}$ instrument (model XP40, Olympus KeyMed, Southend-on-Sea, Essex, UK) was used for children aged up to two years, and a $3.6 \mathrm{~mm}$ instrument (model 3C20 or 3C40, Olympus KeyMed) for those age two to five years. Both bronchoscopes have a $1.2 \mathrm{~mm}$ suction channel. If bronchial lavage was done, this was from the right middle lobe unless the findings indicated an alternative more appropriate site. Three aliquots of $1 \mathrm{ml} / \mathrm{kg} 0.9 \%$ saline were used. After lavage, up to six endobronchial biopsies were taken, using biopsy forceps FB-56D-1 (Olympus KeyMed), from the subcarinae of the right lower lobe, unless a specific lesion appropriate for biopsy was identified elsewhere. The forceps were passed through the suction channel, and biopsies were taken under direct vision at the junction of the subcarinae. The biopsy forceps were closed at the subcarinae for approximately two to three seconds before removal.

\section{Postoperative care}

Patients were observed initially in the theatre recovery area, and subsequently on the ward. Regular observations were carried out for at least four hours after the procedure.

\section{Complications}

Any complications that occurred during the general anaesthetic were recorded prospectively on a data sheet. Any later complications were identified from the nursing observation charts and medical notes.

\section{Histology}

Biopsies were fixed in 10\% formal saline solution overnight and processed into paraffin blocks. Three $5 \mu \mathrm{m}$ sections were then taken at 25 to $50 \mu \mathrm{m}$ intervals, dependent on biopsy size. Sections were stained using haematoxylin and eosin and assessed semiquantitatively by a consultant histopathologist (AGN) for the presence or absence of the following histological features: epithelium, reticular basement membrane, subepithelial stroma and inflammatory cells, submucous glands, and smooth muscle. For each subject, the length of reticular basement membrane was measured in the largest biopsy obtained using image analysis (NIH image 1.55, Maryland, USA).

\section{Analysis}

The two groups were frequency matched to ensure similar demographic characteristics, and complications occurring in the groups were compared using the $\chi^{2}$ test with Yates correction. ${ }^{18}$

\section{RESULTS}

Thirty three children (17 boys, 16 girls) who underwent endobronchial biopsy were identified, and matched with 33 controls ( 22 boys, 11 girls). The indications for bronchoscopy are listed in table 1. All the biopsy patients and 30 of the 33 controls had bronchoalveolar lavage.

Details of the anaesthetic are listed in table 2. There was no difference between groups in the number of patients who had a complication during the procedure, or in the severity or type of complications.

There was also no significant difference in the number, type, or severity of complications occurring after the procedure (table 3 ). One patient from each group needed
Table 1 Indication for bronchoscopy

\begin{tabular}{lll}
\hline & $\begin{array}{l}\text { Biopsy group } \\
(\mathbf{n}=33)\end{array}$ & $\begin{array}{l}\text { Controls } \\
\text { (n=33) }\end{array}$ \\
\hline Wheeze & 8 & 1 \\
Recurrent LRTI & 7 & 9 \\
Cough* & 12 & 9 \\
?TB & 3 & 0 \\
Stridor/noisy breathing & 0 & 6 \\
Tachypnoea & 0 & 1 \\
Cystic fibrosis & 0 & 2 \\
Cystic lesion right lung & 0 & 1 \\
Haemoptysis & 1 & 0 \\
Wheeze and cough & 1 & 4 \\
Abnormal CXR & 1 & 0 \\
\hline \multirow{2}{*}{ *These patients' predominant symptom was cough; however, they also } \\
had associated symptoms of recurrent infections and frequent \\
admissions. The combination of symptoms was the reason for \\
bronchoscopy. \\
CXR, chest $x$ ray; LRTI, lower respiratory tract infection; TB, tuberculosis.
\end{tabular}

Table 2 Details of anaesthetic

\begin{tabular}{|c|c|c|c|}
\hline & $\begin{array}{l}\text { Biopsy group } \\
(n=33)\end{array}$ & $\begin{array}{l}\text { Controls } \\
(n=33)\end{array}$ & p value \\
\hline \multicolumn{4}{|l|}{ General anaesthetic technique } \\
\hline Inhaled & 31 & 30 & \\
\hline Intravenous & 2 & 1 & \\
\hline Not recorded & 0 & 2 & \\
\hline \multicolumn{4}{|l|}{ Maintenance } \\
\hline Inhaled & 32 & 32 & \\
\hline Intravenous & 0 & 0 & \\
\hline Intravenous and inhaled & 1 & 0 & \\
\hline Not recorded & 0 & 1 & \\
\hline Muscle relaxant used & 0 & 3 & \\
\hline \multicolumn{4}{|l|}{ Airway } \\
\hline Face mask (FM) & 25 & 27 & \\
\hline Laryngeal mask (LM) & 8 & 3 & \\
\hline Endotracheal tube & 0 & 1 & \\
\hline$F M$ and $L M$ & 0 & 2 & \\
\hline \multicolumn{4}{|l|}{ Complications $^{*}$} \\
\hline \multicolumn{4}{|l|}{ Total number of subjects with } \\
\hline$(>10 \mathrm{~kg})$ & $(4 / 26)$ & $(6 / 26)$ & 0.00 \\
\hline$i<10 \mathrm{~kg})$ & $(2 / 7)$ & $(2 / 7)$ & \\
\hline \multicolumn{4}{|l|}{ Details of complications $\uparrow$} \\
\hline Desaturation $\ddagger$ & 2 & 3 & \\
\hline $\begin{array}{l}\text { Desaturation needing airway } \\
\text { change }\end{array}$ & 0 & $2 \S$ & \\
\hline Laryngospasm & 1 & 19 & \\
\hline Apnoea & 2 & 0 & \\
\hline Bronchospasm & 0 & 0 & \\
\hline Cough & 3 & 6 & 0.28 \\
\hline Pneumothorax & 0 & 0 & \\
\hline Bleeding & 0 & 0 & \\
\hline \multicolumn{4}{|c|}{$\begin{array}{l}\text { *No significant difference found between groups. } \\
\text { †Subjects may have had more than one complication. } \\
\text { †Transient desaturation }>10 \% \text { below baseline. } \\
\text { §Desaturation requiring change from face mask to laryngeal mask. } \\
\text { - Laryngospasm requiring muscle relaxant prior to improvement. }\end{array}$} \\
\hline
\end{tabular}

transfer to the paediatric intensive care unit overnight for observation, but none required positive pressure ventilation. The main complication after bronchoscopy was the development of fever above $38.5^{\circ} \mathrm{C}$. There were no incidences of significant bleeding or pneumothorax in the biopsy group. The latter was confirmed on chest $x$ ray in 20 patients. Chest $x$ ray was done in these 20 after the bronchoscopy to assess the position of a pH probe, which had been passed under general anaesthesia after the bronchoscopy. (Chest $x$ ray is not routinely requested after bronchoscopy.) Additionally, when all 66 patients were considered together, there were no significant differences in complications occurring between children under or over $10 \mathrm{~kg}$ in weight. 


\begin{tabular}{|c|c|c|c|}
\hline & Biopsy group & Controls & p value \\
\hline \multirow{3}{*}{$\begin{array}{l}\text { Total number with } \\
\text { complication } \\
(>10 \mathrm{~kg}) \\
(<10 \mathrm{~kg})\end{array}$} & $13 / 33$ & $7 / 33$ & 0.18 \\
\hline & $(9 / 26)$ & $(5 / 26)$ & 0.35 \\
\hline & $(4 / 7)$ & $(2 / 7)$ & 0.59 \\
\hline Pyrexia & 10 & 6 & 0.39 \\
\hline Grunting & 1 & 0 & \\
\hline Desaturation & 1 & 1 & \\
\hline Stridor & 1 & 0 & \\
\hline \multicolumn{4}{|l|}{ Treatment (other than } \\
\hline $\begin{array}{l}\text { paracetamol) } \\
\text { Antibiotics }\end{array}$ & 5 & $\begin{array}{l}4 \\
3\end{array}$ & \\
\hline Oxygen - on ward & 3 & 1 & \\
\hline To PICU for observation & $\begin{array}{l}1 \text { (severe } \\
\text { laryngomalacia) }\end{array}$ & $\begin{array}{l}1 \text { (thick } \\
\text { secretions) }\end{array}$ & \\
\hline Dexamethasone & 1 & 0 & \\
\hline
\end{tabular}

\section{Histology}

Suitable biopsies for assessment were available for 30 of the 33 patients. Of the other three, the amount of sampled tissue was too small for histological processing in one case, wholly obscured by crush artefact in one, and contained necrotic cell debris related to tuberculosis in the third. In the 30 suitable specimens, reticular basement membrane was present in all 30 , with at least $1 \mathrm{~mm}$ of basement membrane in 21 . Sufficient subepithelial stroma for assessment of inflammation was present in 26. Areas of smooth muscle were present in 23, and submucous glands were identified in 22 . There was no clear relation between the number of biopsies taken from each subject and the overall biopsy quality (table 4). Details on the value of the information obtained from biopsies in planning further management for the individual are given in table 5.

\section{DISCUSSION}

This report shows that in preschool children undergoing bronchoscopy and bronchoalveolar lavage under general anaesthetic in a tertiary centre, endobronchial biopsy carries no extra risk. In addition, biopsies obtained from this age group are of sufficient quality to assess several different structures in the airway wall.

To our knowledge, this is the first report of the safety of undertaking endobronchial biopsy in preschool children. It is important to highlight the safety of the procedure in addressing ethical issues raised by research involving endobronchial biopsy in preschool children. Complications are not uncommon in young children undergoing bronchoscopy. Carrying out an endobronchial biopsy as well could cause additional complications, as the anaesthetic may be more prolonged and the procedure itself may carry risks. The inclusion of a matched control group subjected to exactly the same procedures but without endobronchial biopsy was therefore an essential part of the study. However, there was

Table 4 Biopsy quality in relation to the number of biopsies taken

\begin{tabular}{ll}
\hline Biopsies taken $(\mathbf{n})$ & $\begin{array}{l}\text { Proportion of subjects in whom all } \\
\text { structures could be assessed }\end{array}$ \\
\hline $5-6$ & $50 \%$ \\
4 & $60 \%$ \\
3 & $72 \%$ \\
2 & $43 \%$ \\
1 & $60 \%$ \\
\hline
\end{tabular}

Table 5 Influence of biopsy report on subsequent patient management

\begin{tabular}{|c|c|c|}
\hline $\begin{array}{l}\text { Bronchoscopy } \\
\text { indication }\end{array}$ & $\begin{array}{l}\text { Management } \\
\text { influenced by biopsy } \\
\text { result }\end{array}$ & $\begin{array}{l}\text { Management } \\
\text { unchanged by biopsy } \\
\text { result }\end{array}$ \\
\hline Cough \pm wheeze & 14 & 4 \\
\hline Recurrent LRTI & 2 & 7 \\
\hline
\end{tabular}

no significant difference in the number, type, or severity of complications between the groups. The main complication seen after the procedure was the development of a fever. This is a recognised complication of bronchoalveolar lavage, ${ }^{19}$ which was done in all biopsy patients and in 30 of the 33 controls. As there was no difference between the groups in the incidence of fever, it is most likely that this complication was a result of the lavage rather than of the biopsy. Furthermore, the complications that are thought to be specifically associated with performance of biopsy, for example bleeding, were not seen in any of the biopsy group. This is in contrast to transbronchial biopsy, which carries a small but definite risk of bleeding and pneumothorax. ${ }^{20}{ }^{21} \mathrm{We}$ do not advocate the use of transbronchial biopsy as a research procedure in children.

It must also be stressed that all bronchoscopies were done in a tertiary centre, with trained personnel, and the general anaesthetic was given by consultant paediatric anaesthetists. Anaesthetic details and complications during bronchoscopy have been collected prospectively at the time of the procedure at our centre for the last five years. Information on any complications occurring after the procedure was obtained retrospectively, and therefore depended on the accuracy of the medical notes.

This report is in agreement with others that have shown that flexible bronchoscopy and bronchoalveolar lavage in children is safe, ${ }^{19}$ as is endobronchial biopsy in older children. ${ }^{1722} 23$ In contrast to the findings of Gibson and colleagues, ${ }^{24}$ when we considered all patients (biopsy group and controls), we did not find any significant difference in complications occurring in children under or over $10 \mathrm{~kg}$ in weight (data not shown). In the present study, safety was maximised by the use of a general anaesthetic given by a senior paediatric anaesthetist. Although sedation is an alternative, ${ }^{19}$ the use of a general anaesthetic allows the bronchoscopist to focus on the procedure while the airway is managed by an anaesthetist, and almost always ensures successful completion with minimal discomfort for the child. ${ }^{25}$

We believe this is the first report of biopsy quality in preschool children. Up to six endobronchial biopsies were taken in each case. There was no clear relation between the number of biopsies taken and the overall biopsy quality for an individual. The results suggest that no additional clinical information is obtained by taking more than three biopsies per subject. However, more may be required for research studies, depending on the hypothesis to be tested and the laboratory techniques used. Reticular basement membrane, the thickness of which is often used as a marker of airway remodelling, ${ }^{11}$ was identified in all 30 biopsies that could be assessed (fig 1). In 21 of the 30, the length of reticular basement membrane was at least $1 \mathrm{~mm}$, which is the minimum length recommended for research studies. ${ }^{26}$ Sufficient subepithelial stroma for assessment of the presence of inflammatory cells was seen in 26 of the 30 specimens. Smooth muscle was present in 23 cases (fig 2). This is very similar to the figure of $78 \%$ from Payne et al in older children. ${ }^{13}$ Epithelium was the only structural feature 


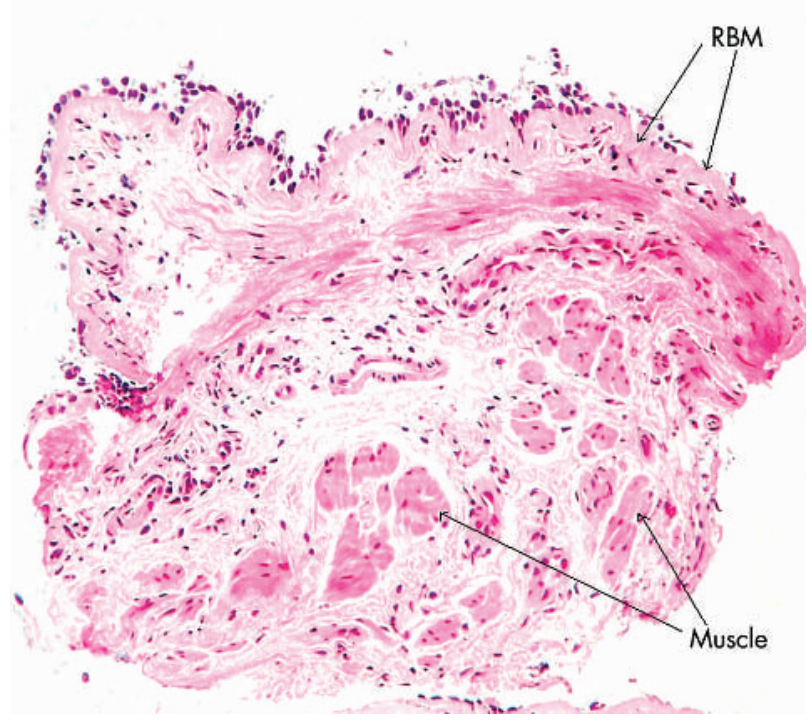

Figure 1 Low power view of an endobronchial biopsy section from a three year old child, showing thickening of the reticular basement membrane (stained with haematoxylin and eosin).

not seen consistently, and was only present in 18 of the 30 biopsies. This is often the case, even in biopsies obtained from adults with larger biopsy forceps. ${ }^{11}$

Our main aims in this report were to evaluate the safety of endobronchial biopsy in preschool children and assess the quality of the biopsies obtained. However, the results also provide some indication of the clinical value of endobronchial biopsy in this age group, although the retrospective nature of this report is a weakness. Endobronchial biopsy was done as one of several investigations, which included bronchoscopy, bronchoalveolar lavage, and if appropriate, $\mathrm{pH}$ study and chest computed tomography. Information obtained (for example, the pattern of inflammation, reticular basement membrane thickness) from endobronchial biopsy was most useful in the evaluation of children with recurrent cough or

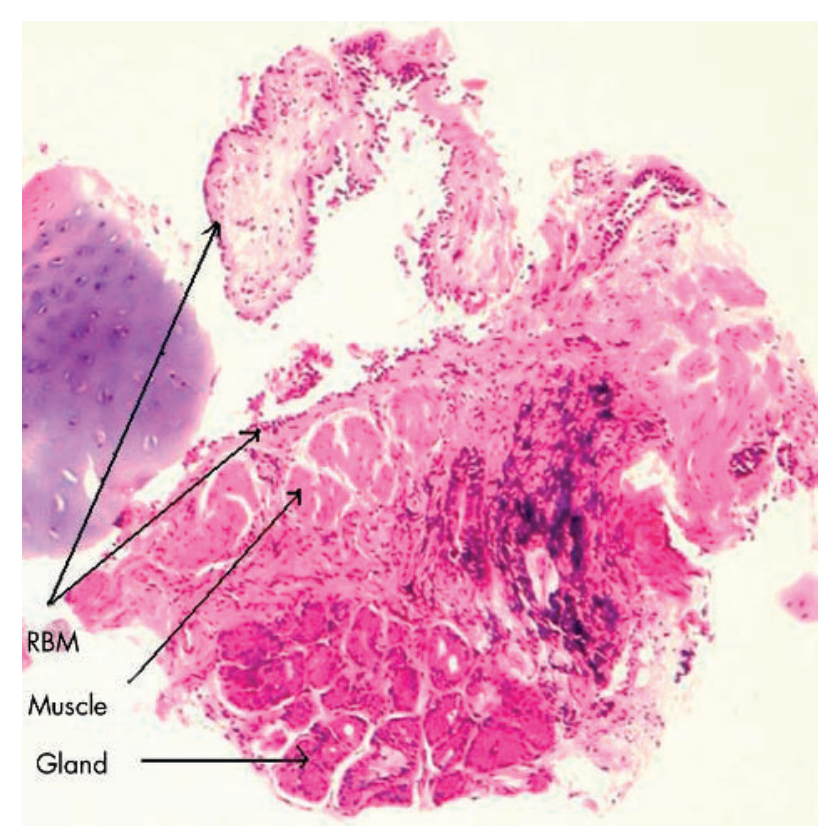

Figure 2 Low power view of an endobronchial biopsy section from a 17 month old child (stained with haematoxylin and eosin). wheeze, in whom a decision on the initiation or withdrawal of treatment with inhaled corticosteroids was being considered.

\section{Conclusions}

We have shown that in infants and preschool children endobronchial biopsy during flexible bronchoscopy carries no extra risk, and that the quality of biopsies obtained is sufficient to allow an assessment of airway remodelling and inflammation. It is important to emphasise that the study was done in a tertiary centre with appropriately trained personnel and specialist laboratory facilities. Any future research using endobronchial biopsy to investigate the pathology of wheezing disorders in this age group should be restricted to such centres, ${ }^{27}$ with collaboration between departments in order to maximise the use of samples and minimise the number of subjects enrolled. Studies involving comparison of invasive and non-invasive techniques should also be encouraged, to validate the latter for use in future research. ${ }^{28}$

\section{ACKNOWLEDGEMENTS}

We are grateful to Dr Rudiger Stenz for his help in obtaining information from the anaesthetic database.

\section{Authors' affiliations}

S Saglani, D N R Payne, A Bush, Department of Paediatric Respiratory Medicine, Royal Brompton Hospital, London SW3, UK

A G Nicholson, Department of Histopathology, Royal Brompton Hospital M Scallan, E Haxby, Department of Anaesthetics, Royal Brompton Hospital

\section{REFERENCES}

1 Kuehni CE, Brooke AM, Silverman M. Prevalence of wheeze during childhood: retrospective and prospective assessment. Eur Respir J 2000;16:81-5.

2 Luyt DK, Bourke AM, Lambert $P$, et al. Wheeze in preschool children: who is followed-up, who is treated and who is hospitalized? Eur Respir J 1995; 10:1736-41.

3 Stein RT, Holberg CJ, Morgan WJ, et al. Peak flow variability, methacholine responsiveness and atopy as markers for detecting different wheezing phenotypes in childhood. Thorax 1997;52:946-52.

4 Martinez FD. Development of wheezing disorders and asthma in preschool children. Pediatrics 2002;109:362-7.

5 Martinez FD, Wright AL, Taussig $L M$, et al. Asthma and wheezing in the first six years of life. N Engl J Med 1995;332:133-8.

6 Castro-Rodriguez JA, Holberg CA, Wright AL, et al. A clinical index to define risk of asthma in young children with recurrent wheezing. Am J Respir Crit Care Med 2000;162:1403-6.

7 Clough JB, Keeping KA, Edwards LC, et al. Can we predict which wheezy infants will continue to wheeze? Am J Respir Crit Care Med 1999;160:1473-80.

8 Nielson KG, Bisgaard $\mathrm{H}$. The effect of inhaled budesonide on symptoms, lung function, and cold air and methacholine responsiveness in 2- to 5-year-old asthmatic children. Am J Respir Crit Care Med 2000;162:1500-6.

9 De Jongste JC, Janssens HM, Van der Wouden J. Effectiveness of pharmacotherapy in asthmatic preschool children. Allergy 2002; suppl 74:42-7.

10 Jeffery PK, Wardlaw AJ, Nelson FC, et al. Bronchial biopsies in asthma. An ultrastructural, quantitative study and correlation with hyperreactivity. Am Rev Respir Dis 1989;140:1745-53.

11 Bousquet J, Jeffery PK, Busse WW, et al. Asthma. From bronchoconstriction to airways inflammation and remodeling. Am J Respir Crit Care Med 2000;161:1720-45.

12 Cokugras $H$, Ahcakaya N, Seckin, et al. Ultrastructural examination of bronchial biopsy specimens from children with moderate asthma. Thorax 2001;56:25-9.

13 Payne DNR, Rogers AV, Adelroth E, et al. Early thickening of the reticular basement membrane in children with difficult asthma. Am J Respir Crit care Med 2003; 167:78-82.

14 Payne DN, Adcock IM, Wilson NM, et al. Relationship between exhaled nitric oxide and mucosal eosinophilic inflammation in children with difficult asthma, after treatment with oral prednisolone. Am J Respir Crit Care Med 2001;164:1376-81.

15 Bisgaard H. Persistent wheezing in very young preschool children reflects lower respiratory inflammation. Am J Respir Crit Care Med 2001;163:1290-1.

16 McKay KO, Hogg JC. The contribution of airway structure to early childhood asthma. Med J Aust 2002;177:S45-7.

17 Payne D, McKenzie SA, Stacey S, et al. Safety and ethics of bronchoscopy and endobronchial biopsy in difficult asthma. Arch Dis Child 2001;84:423-6. 
18 Altman DG Practical statistics for medical research. London: Chapman and Hall, 1991:252-3.

19 de Blic J, Marchac V, Scheinmann P. Complications of flexible bronchoscopy in children: prospective study of 1328 procedures. Eur Respir J 2002;20:1271-6.

20 Scott JP, Higenbottam TW, Smyth RL, et al. Transbronchial biopsies in children after heart-lung transplantation. Pediatrics 1990;86:698-702

21 Whitehead B, Scott JP, Helms P, et al. Technique and use of transbronchial biopsy in children and adolescents. Pediatr Pulmonol 1992;12:240-6.

22 Bush A, Pohunek P. Brush biopsy and Mucosal biopsy. Am J Respir Crit Care Med 2000;162:S18-22.

23 Salva PS, Theroux CA, Schwartz D. Safety of endobronchial biopsy in 120 children with chronic respiratory symptoms [abstract]. Am J Respir Crit Care Med 2002; 165:A163.
24 Gibson NA, Coutts JA, Paton JY. Flexible bronchoscopy under $10 \mathrm{~kg}$. Respir Med 1994;88:131-4

25 Stacey S, Haxby E, Bush A. Sedation for paediatric bronchoscopy. Chest $2001 ; 119: 316-17$.

26 Sullivan $\mathbf{P}$, Stephens $D$, Ansari T, et al Variation in the measurements of basement membrane thickness and inflammatory cell number in bronchial biopsies. Eur Respir J 1998;12:81 1-15.

27 Jeffery $\mathbf{P}$, Holgate S, Wenzel S. Methods for the assessment of endobronchial biopsies in clinical research: application to studies of pathogenesis and the effects of treatment. Am I Respir Crit Care Med 2003;168:S1-17.

28 Davies J, Payne D. Research application of bronchoscopy. Paediatr Respir Rev 2003;4:230-6

\section{LUNG ALERT}

Peak flow may be useful in screening for COPD in the absence of spirometry

$\Delta$ Jackson $\mathrm{H}$, Hubbard R. Detecting chronic obstructive pulmonary disease using peak flow rate: cross sectional survey. BMJ 2003:327:653-4

$\mathrm{T}$ his short paper analysed data from the third National Health and Nutrition Survey (NHANES III). A total of 3874 subjects aged 50-90 years were included and their percentage predicted forced expiratory volume in 1 second $\left(\mathrm{FEV}_{1}\right), \mathrm{FEV}_{1} / \mathrm{FVC}$ ratio, peak flow rate (PEF), smoking history, and respiratory symptoms were analysed using specialised statistical techniques (see www.cdc.gov/nchs/data/nhanes/nhanes3/cdrom/nchs/manuals/ nh3guide.pdf for further details). 265 subjects with COPD (7.8\% prevalence; 54\% male; mean age 65 years) were identified, of whom 235 had a PEF of less than $80 \%$ predicted. The adjusted sensitivity for detecting all subjects with COPD was $91 \%$, and for moderate to severe COPD ( $\mathrm{FEV}_{1} \leqslant 59 \%$ predicted) it was $100 \%$. The specificity of an abnormal PEF was $82 \%$, although $62 \%$ of the false positive cases were smokers and $47 \%$ had airflow obstruction on spirometry, but less than that required to make a diagnosis of COPD.

The authors suggest that using PEF as a screening method for COPD in primary care could save money for interventions such as smoking cessation strategies instead of using resources for the provision of spirometric tests. Other studies have previously shown that exacerbations of COPD are associated with a significant fall in PEF, so it is reasonable to state that PEF measurements may prove to be a more valuable tool in the diagnosis and/or monitoring of COPD than was previously recognised.

\section{A Bhowmik \\ London Chest Hospital, London A.Bhowmik@qmul.ac.uk}

\subsection{3 million died from smoking related disease in $\mathbf{2 0 0 0}$}

A Ezzati M, Lopez AD. Estimates of global mortality attributable to smoking in 2000. Lancet 2003;362:847-52

U sing lung cancer mortality as an indirect marker for smoking risk, Ezzati and Lopez expanded the Peto-Lopez method to estimate global mortality due to smoking in 2000. The American Cancer Society Prevention Study and the work of Liu et al in China were used to calculate relative risks and these were corrected for confounding variables.

They estimated $12 \%$ of total global deaths were attributable to smoking (4.83 million). Roughly equal numbers of people died of smoking related disease in the industrialised and developing worlds (2.43 and 2.41 million, respectively); men accounted for $84 \%$ of these deaths in the developing world and 74\% in the industrialised world. 2.69 million people died aged 30-69 years, resulting in a substantial loss of productive years. The leading causes of death from smoking were cardiovascular disease ( 1.69 million), chronic obstructive pulmonary disease ( 0.97 million), and lung cancer ( 0.85 million).

The percentage of deaths due to smoking is currently higher in the industrialised world (19\%) than in the developing world $(9 \%)$, but this is likely to change as the rate of smoking increases in the developing world. Initiatives are desperately needed to reduce the rate of smoking in men and to prevent increases in women.

J M Douse 